\title{
AN ANDROID APPLICATION FOR VOLUNTEER BLOOD DONORS
}

\author{
Sultan Turhan \\ Department of Computer Engineering, \\ GalatasarayUniversity, İstanbul, TURKEY \\ sturhanegsu.edu.tr
}

\begin{abstract}
There is an expectation that the blood will always be there when it is really needed. Blood donor volunteers constitute the main supply source in an effective blood supply chain management. They feed blood stocks through their donation. In an emergency situation, if the stocks are insufficient, the only source of blood supply will be the people who come to the health center and donate the blood on a voluntary basis. It is certain that time is a very important component in such situation. For this reason, the health care center should call the nearest available donor in order to ensure to get the service as quickly as possible. A smart phone application is developed to facilitate the identification of the nearest available blood donor volunteer and the communication with him/her in the emergency situations where the blood can't be supplied through the blood banks' stocks. In this paper this application will be presented.
\end{abstract}

\section{KEYWORDS}

Smart phone application, Blood donation information system, optimization, distance calculation, java development platforms

\section{INTRODUCTION}

Despite all the advances in medicine and technology, an alternative medical way to substitute blood, blood components or blood-derived products have not been found yet [2]. Blood can only be supplied by living donors. Blood transfusion has been responsible for saving millions of lives each year around the world. Yet the quantity and quality of blood pool available for transfusion is still a major concern across the globe, especially in the developing countries [3]

According to Turkish Red Crescent Society (TürkKızılay1)[13], the estimated blood requirement for Turkey is about 2.100 .000 unit per year and the organization can fulfill $85 \%$ of this requirement thanks to volunteer blood donors. There are three types of blood donors in Turkey: a) voluntary donors, b) replacement donors, and c) professional donors [3]. Most donations are as a result of replacement donations provided by the relatives of patients. In case of operation or treatment, health care center employees asked to patient's relatives to donate blood even they don't have the same blood group. Professional donors are those who donate blood in exchange for money. Unfortunately these two types of blood donors don't help maintaining a reliable stock of blood. Moreover, they do not provide rare blood groups. These points indicate the need and importance of voluntary blood donations [6]. Voluntary donors are non-remunerated donors and donate blood voluntarily without any inducements such as money or any other substitute of

Jan Zizka et al. (Eds) : CCSEIT, MoWiN, IT, AIAP, ICBB - 2015

pp. 23-30, 2015. (C) CS \& IT-CSCP 2015

DOI : $10.5121 /$ csit.2015.51103 
money [10]. Such donations are providing adequate round the clock availability during emergency situations and they are the source of safe blood also. The sustainability of a safe and adequate blood supply is still provided by volunteer blood donors [9].

Almost all over the world, blood recruitment services are conducted in a systematic way. Compared to worldwide applications, Turkey has not been reached yet to a desired level. There are 297 blood centers across Turkey [10]. They are mostly in big cities like İstanbul, Ankara and İzmir. In little cities and provinces, Turkish Red Crescent Society manages the blood recruitment. Unfortunately there isn't any coordination between all these institutions and the blood recruitment and supply management keep still their unsteadiness between shortage and wastage. On the other hand, in an emergency situation or a chronic disease case, when the blood stocks are insufficient to fulfill the requirement, the blood is supplied via public announcement through the traditional or social media, which may not always result in a successful way [12].

In order to maintain continuously blood recruitment, blood banks should implement different campaign for encouraging people to become a registered volunteer donor [5]. Also, they have to facilitate blood donation process with help of new technology in order to increase the volunteer donors' willingness and accessibility [3]. Market research experts define the different generations found in the blood donor population. The common characteristic of a large part of this population is to be digital natives whose smart phones are ubiquitous.

$\mathrm{Rh}++[1]$ is an integrated information system whose aim is to manage the blood donation and blood supply chain. The proposed system is used by the patients and/or relatives of the patients to notify their blood requirements and by the living donors to be aware of these requirements. When the blood request is defined into the system, the system checks the stock of the blood banks in the neighborhood. In this way, the system can declare quickly weather the blood needed can be supplied or not. If the blood needed cannot be supplied from the neighborhood blood banks, the system send request to living donors of the same region, via the mobile application installed in donors' smart phones and interprets the response coming from the donors. If there is any affirmative answer from the living donors, the system informs the related health care provider.

$\mathrm{Rh}++$ seeks to provide services to different kind of user such as healthcare institutions, blood banks, volunteer donors, patients or their relatives. Therefore, its infrastructure is designed as flexible as possible, in order to ensure data exchange easily between the organizations, each of them has different infrastructure architecture. For this reason, Service Oriented Architecture principles [13] are adopted directly in infrastructure architecture as well as process designs. The system consists of a backbone which provides data exchanges between different kind of information systems, a web portal and mobile phone's applications which ensure the user interaction.

\section{SMART PHONES’ APPLICATION FOR VOLUNTEER DONORS}

\subsection{Operating System}

We chose to use the Android software stack produced by Google. Android is an open source framework designed for mobile devices that packages an operating system, middleware, and key applications [15]. The Android SDK provides libraries needed to interface with the hardware and make/deploy an Android application [16]. Applications are written in Java. Android uses a SQLite database to store persistent data. Unlike dedicated systems, our software is intended to integrate with the phone's existing applications. Our application must share resources with the other application. To make for a pleasant integration, the application runs as inconspicuously as possible while using limited resources. We launch a background service that constantly listens to the web services. Only when the algorithm described in the following section receive a request, 
will the service wake up and interrupt the user. By only waking up the activity when a request is defined, we allow applications to run on top of our application while we minimize our memory consumption and user interaction.

\subsection{General Description}

The application is developed for the smart phones using Android operating system. The main duty of the application is to notify regularly the donor's location to $\mathrm{Rh}++$. The process of being a registered donor of $\mathrm{Rh}++$ consists of following tasks: Volunteer uses $\mathrm{Rh}++$ 's web portal interface to be registered as donor into the system. $\mathrm{Rh}++$ is a smart information system, and all users' interventions are minimized. Nevertheless, following the registration, volunteer is called by blood recruitment center's staff and required to pass the routine health checks. If his/her health condition is suitable to be a donor, blood center gives the username and password to the volunteer and s/he downloads the application into his/her smart phones. The following picture illustrates the login screen of the Android application.

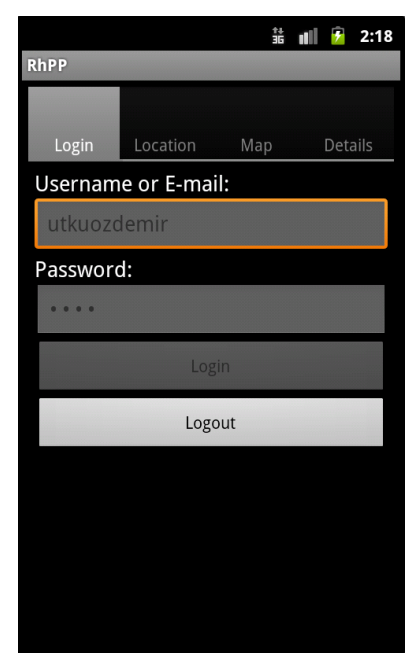

Figure 1.Login Screen of Mobile Application

Once donor connects to the system, the application downloaded into his/her smarts phone starts to send his/her location information to the main system. Two of the common problems in mobile phones' applications are the optimization of battery usage and mobile data exchange. In order to control these two usages, the update frequency of volunteer donor's location information is let under the control of the user. Donor may decrease the update frequency if $s /$ he is idle in a specific location (work, home, theater etc.) or increase it, if $\mathrm{s} / \mathrm{he}$ is on the move. Also, volunteer donor may update his/her own location information using "Update My Location Now" button on the above mentioned screen whenever s/he wants. Figure 2 illustrates the "Update Frequency" screen. 


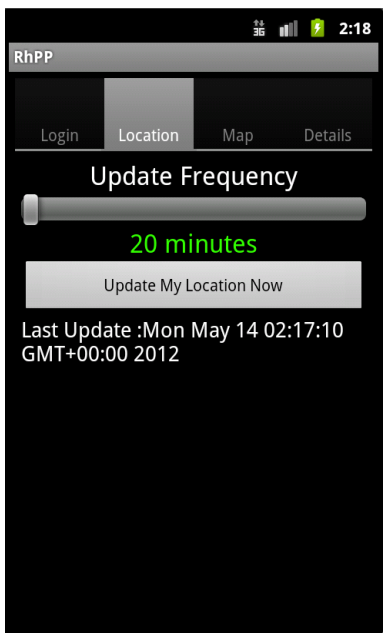

Figure 2.Update Frequency Period Screen

When a blood request comes to the system and if it cannot be supplied from the stocks, the system checks the donors' location, determines the nearest ones and sends them the alerts. Donors receive this alert and respond affirmatively or negatively via their application. Thanks to this rapid communication, the system may first dedicate if the blood can be supplied or not, and secondly calculate the acquisition time of the necessary blood. When the volunteer donor answers affirmatively, the requester health center's information is sent to donor's smart phones

\subsection{Technical Details}

The application has been initially developed on Android Studio using ANT. Application has two major tasks: a) sending periodically donor's location information to $\mathrm{Rh}++$ and $\mathrm{b}$ ) receiving alerts from $\mathrm{Rh}++$. To determine the donor's latitude and longitude values, we included maps feature to our applications and we chose to implement Google's maps services. Figure 3 illustrates the map screen.

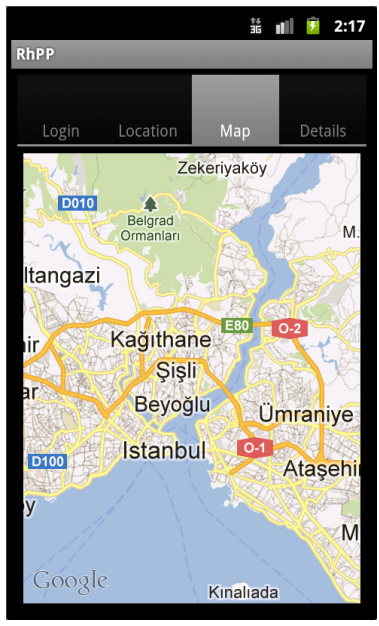

Figure 3. Map Screen 
To find the nearest available donor to the requester health center, the system calculates the distance between the requester health center and the donor. It is Euclidian distance calculation. The data exchange between the application and the main system is provided by the web services.

Two web services are generated for this operation:

- public String getNearestDonorsToHospital (intuserID, inthospitalID, int radius, intcheckedInLastNHours, String bloodGroup, String bloodType): This web service is responsible to determine the nearest donors to the requester healthcare center. In order to make this calculation, the web service gets the healthcare center location's information, requested blood information and the radius value determined by the user. With all this input, the web service determine the name, surname and location information of the donors who are suitable, close to the requester healthcare center andupdated his/her location at most checkedInLastNHours time period ago.

- public StringgetNearestDonors (intuserID, double latitude, double longitude, int radius, intcheckedInLastNHours, String bloodGroup, String bloodRH): This web service realize the same operation as the above one. The only difference between them is that in this web service the central point is not a registered healthcare center but it is a specific point of which the longitude and latitude value are defined by the users.

It is important to specify that Android cannot support natively the communication established with web services. For this reason, we use a specific open source WSDL library, ksoap2-android, to call web service s from the Android applications.

\section{OPTIMIZATION}

\subsection{Distance Calculation}

In the initial system, to find the nearest volunteer donor in order to send the call request, the system calculates the distance as crow flies using both the healthcare centers and the living donors' coordinates. To determine the location of nearest donor, calculating the distance as crow flies was effectual on the paper, but some problems -such as traffic jam, physical conditions, or road conditions- appear when it is put into real life practice. Calculating the distance as crow flies isn't sufficient for the system. So an optimization in distance calculation is decided. Previously, to calculate the distance, requester healthcare coordinates was taken as the coordinates of the circle drawn virtually on the map with the radius of which the length is determined by the user. Then, appropriate ones among the donors whose coordinates are in the area covered by this circle are selected. As it can be easily understand from Figure 4, being in the area covered by the virtual circle does not mean that the donor can reach the hospital in real life. For this reason, an adjustment is made by taking actual road conditions into account and the Google maps functions are inserted into distance calculation. This calculation helps to determine not only nearest volunteer living donor but the most realistic one. It should be noticed that one of the most important constraints in this system is the time. Any optimization or improvement on nearest donor determination will be vital in emergency cases.

\subsection{Development Environment}

The second improvement on the system is made for Android's users. As everyone agrees, many software and hardware products cannot meet the requirements of the new technologies because of its fast development. Even in the case they are sufficient to meet the requirements, ensuring the 
integration between different kind of material and software requires really a hard work and the process takes time.

The initial system has been developed on Android Studio using ANT[18]. It is one of the oldest Java library and command-line tool whose mission is to drive processes described in build files as targets and extension points dependent upon each other.There are several building tools such as ANT, Maven or Ivy. Each of them has its own strengths and weaknesses. ANT has a very flexible structure but it is the developer's job to determine every development step. Also, it doesn't have the library management. For example, if the project needs a library with .jar extension, finding these related .jar files and copying them to relevant directories is entirely under developer's responsibilities. Maven [19] enforces a standardized project layout. This saves time getting new people working on the projects. It provides automatic resolution of dependencies which are cached so that if there are multiple projects, there is no need to keep making local copies. Maven also promotes the concept of a resource repository and can create complex products with minimal direction. Also, the build environment is pretty portable but it has a very standardized layouts. This causes a real problem if the project has an unusual type. It's very easy to make the library management and move the project on Maven in case if the project complies totally with Maven's compelling structure. Gradle [17] is a build automation framework which brings together the strengths of all above mentioned building tools. It offers both ANT's flexibility and library management without Maven's coercion. It easily allows the developer to create .jar and/or .war files using the project's source code, run the test and integrate the add-on or other programs. As it uses Maven's library management, it ensures simple organization of .jar files' part. Another advantage provided by Gradle is the ability of managing multiple projects in a simple way. It has a solid infrastructure to enable to integrate any existing project without structural changes.

Therefore, in order to guarantee a successful result of the improvements made on the project, the system has been carried on integrated development framework Gradle. Besides, as the technology evolves, many of old systems have been removed on Gradle which offers better performance.

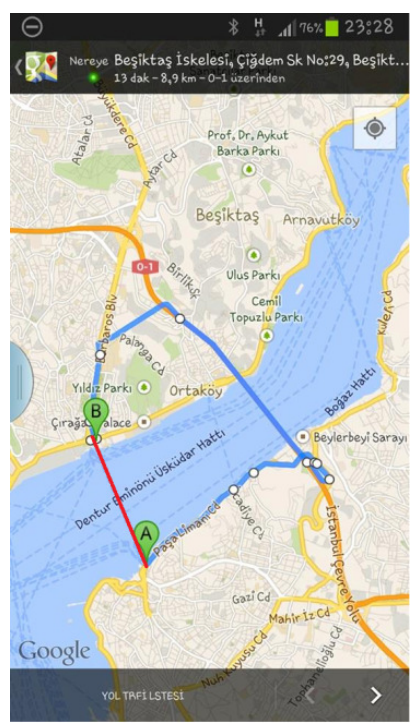

Figure 3. The difference between distance as crow files and real distance 


\section{CONCLUSIONS}

In this study, we presented a smart phone's application for the volunteer blood donor to increase the willingness and accessibility with the purpose of providing a continuous blood supply. This application helps health care centers to provide the blood as quick as possible when their stocks are insufficient. The application sends periodically actual location information of available donors to main system and the blood requests to the donors. In this way, it provides an uninterrupted communication between the health care centers and volunteer donors. The distance of the volunteer donors to the healthcare center is an important criterion in the determination of the donors. Therefore an optimization is also realized on this process. In the initial system, the distance calculation is made by taking the distance as crow flies. In the optimized system, it is converted to the actual distance. This optimization makes the system more realistic. The second improvement is performed on the system's infrastructure. Especially, by taking into consideration the rapid development of mobile device technology which uses Android operating system, the system has been carried from the from ANT building environment onto Grade build automation platform. In further studies, we aim the add evaluation of traffic density between living donors' locations and healthcare centers to the living donor selection criteria

\section{ACKNOWLEDGEMENTS}

This research is supported financially by Galatasaray University Scientific Research Project no: 13.401.004 .The author would like to thank Galatasaray University Scientific Research Council for their support.

\section{REFERENCES}

[1] Turhan, S., Ozdemir, U, Yaşar, A., 2012, Kan Bağışı Ve Temini Bilgi Sistemi: Türkiye İçin Mobil Modelleme, Akıllı Sistemlerde Yenilikler ve Uygulamaları Sempozyumu, Trabzon, Turkey, pp.192198

[2] Dutta, D.A. et al., 2011,Artificial Human Blood , Inventi Impact: Pharm Tech, Vol. 2011,No.1

[3] Gillespie, T. W., \& Hillyer, C. D. (2002). Blood donors and factors impacting the blood donation decision. Transfusion Medicine Reviews, 16(2), 115-130.

[4] V. Bosnes, M. Aldrin, H. E. Heier, "Predicting Blood Donor Arrival." , Transfusion, Cilt: 45, Sayı:2, 2005, s. 162-170.

[5] Prcmasudha, B.G., et al., 2010, Application of Spatial Decision Support System to Blood Bank Information Systems, International Journal of Geoinformarics, Vol.6, No. 2, pp.51 - 58.

[6] Sime, S..L. et al., 2005, Strengthening The Service Continuum Between Transfusion Providers and Suppliers: Enhancing the Blood Services Network., Transfusion, Vol.45, No.4, pp.206S-223S.

[7] France, C. R., France, J. L., Wissel, M. E., Kowalsky, J. M., Bolinger, E. M., \& Huckins, J. L. (2011). Enhancing blood donation intentions using multimedia donor education materials. Transfusion, 51(8), 1796-1801.

[8] Stanger, S. H., Yates, N., Wilding, R., \& Cotton, S. (2012). Blood inventory management: hospital best practice. Transfusion medicine reviews, 26(2), 153-163.

[9] Williamson, L. M., \& Devine, D. V. (2013). Challenges in the management of the blood supply. The Lancet, 381(9880), 1866-1875.

[10] Türkiye Kan Merkezleri ve Transfüzyon Derneği, Ulusal Kan ve Kan Ürünleri Rehberi, Haziran 2011, www.kmtd.org.tr

[11] Ş.Hablemitoğlu, Y. Özkan, F. Yıldırım, "Bir Fedakârlık Örneği Olarak "Kan Bağışı” ” , Aile ve Toplum, Ocak - Şubat - Mart 2010, s.67 - 77

[12] Nilsson Sojka, B., \& Sojka, P. (2003). The blood-donation experience: perceived physical, psychological and social impact of blood donation on the donor. Vox Sanguinis, 84(2), 120-128.

[13] Erl, Thomas. Soa: principles of service design. Vol. 1. Upper Saddle River: Prentice Hall, 2008. 


\section{AUTHORS}

Sultan N. Turhan received MSc degree in computational science and engineering in 2003 from Istanbul Technical University and her Ph.D degree in Engineering Management from Marmara University. Between 1992 - 1998, she worked as database administrator, IT project coordinator and IT responsible in different institutions. Between 2002 - 2006, she also worked for Intelitek- Element A.S as academic consultant for distance learning and e-learning platforms. Since 1998, she is working as senior lecturer in Computer Engineering department of Galatasaray University. Currently she is working on developing mob ile software in special education area for

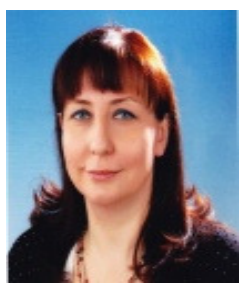
the children with Autism Spectrum Disorder. 